\title{
Thermal Demagnetization of Some Precambrian Igneous Rocks of Missouri
}

\author{
S.A. Vincenz, G.J. Braught and A.C. Meyers III \\ Department of Geophysics and Geophysical Engineering, \\ Saint Louis University, St. Louis, Missouri. U.S.A.
}

\begin{abstract}
The results of a deliberate search for stable secondary magnetization in Precambrian igneous rocks of St. Francois Mountains, Southeast Missouri, U.S.A., are described. These rocks, at least one billion years old, possess stable components of natural remanent magnetization, which are not always of thermoremanent origin. The results of thermal demagnetization and of some subsidiary experiments show that rhyolite porphyries of Flint Hill have been remagnetized by strong fields due to lightning and are of little use for paleomagnetic investigations. Similar experiments conducted on felsites and bedded tuffs of Johnson ShutIns area reveal the presence of stable and significant magnetization of a direction similar to that found by Scharon, Hayes, and Anderson for the whole of St. Francois Mountains. The granite porphyry from the same area carries a stable component of natural remanent magnetization, which is of secondary origin, but is of little significance for the paleomagnetic studies of the whole system of rock units.

It is concluded that the rock units investigated carry no stable secondary magnetization which masks their original magnetization and leads to wrong conclusions about the direction of Precambrian geomagnetic field. From this it is inferred that the natural remanent magnetization of all other rock units of St. Francois Mountains is unlikely to be masked by stable secondary components.
\end{abstract}

\section{Introduction}

One of the arguments used by the critics of paleomagnetic studies is that a stable secondary magnetization of ancient rocks often masks the original natural remanent magnetization (NRM) acquired at the time of their formation. This effect, according to the critics (see, for instance, Hibberd, 1962), leads to wrong conclusions about the direction of the ancient geomagnetic field and thus invalidates some of the hypotheses based on paleomagnetic studies.

A stable secondary magnetization could be produced in several ways. A reheating of the rocks as a result of igneous activity might have taken place, causing partial destruction of the original NRM. Subsequent cooling in an ambient field of different direction would build up a partial thermoremanent magnetization (PTRM) which, combined with the remaining original NRM, would produce a new resultant NRM. The rocks could also have been reheated by deep burial under sediments deposited at a later date. This process, followed by uplift and slow cooling due to erosion of the strata in an ambient field of different direction, would also change their original magnetization. The secondary magnetization 
would in this case take the form of viscous partial thermoremanent magnetization (VPTRM) (Chamalaun, 1964) or chemical remanent magnetization (CRM). In addition, if the rocks were magnetically anisotropic, the original NRM might have been modified by stresses due to burial, cooling, or tectonic processes.

Any one or all of these processes may arise in a specific geologic situation. In some cases it should be possible to correlate such magnetic changes with known geologic events inferred from structural data and visible mineralogical changes. Often there is no geological evidence for these effects and mineralogical changes may be too subtle to be detected by standard petrological techniques. Evidence to date shows that processes of this kind do take place, but in general are not significant. A number of workers have demonstrated that suitable laboratory treatment of NRM will remove the less stable secondary magnetization. An excellent review of this work is given in Irving's "Paleomagnetism" (1964). Some recent applications of the standard techniques are described by McElhinny and Opdyke (1964), Opdyke (1964 a, 1964 b) and Gough et al. (1964).

The study of the more stable secondary magnetization has been conducted by Wilson (1961, 1964), Wilson and Everitt (1963), Chamalaun and Creer (1964) and Chamalaun (1964). Evidently, as established by these workers, high stability secondary components can be removed only by heating to temperatures close to the Curie points of the magnetic constituents carrying the NRM. In some cases, as reported by McElhinny and Opdyke, thermal demagnetization fails to remove the secondary components which are attributed to a stable form of isothermal remanent magnetization (IRM) due to lightning. In this case the intensities of NRM are very high and are more or less scattered in direction. Demagnetization with high alternating fields usually removes this type of secondary magnetization, but in some cases the original NRM cannot be recovered and the magnetization is ascribed to direct hits by lightning.

The investigations described below are concerned with the search for stable secondary magnetization in some selected Precambrian igneous sites in St. Francois Mountains, Southeast Missouri. Clearly, support for the arguments of the critics could only be obtained if complete rock units carry such a magnetization. It must, therefore, be either of thermoremanent origin or a stable CRM not fully erased by formation of multidomain grains due to a continued nucleation process (Nagata, 1961). Presence of unstable CRM, such as that of rocks containing maghemites or titanomaghemites, or of unstable secondary components in the form of viscous remanent magnetiztion (VRM), or an IRM imposed by lightning cannot, of course, provide any support for the critical hypotheses.

\section{Description of the Rocks}

The most up-to-date information on Precambrian igneous geology of Missouri is contained in a memoir shortly to be published by the State of Missouri Geological Survey (Robertson et al., 1965). A review of the geology of St. Francois Mountains of the Ozark Plateau in Missouri can be found in Report No. 26 of the State of Missouri Geological Survey (1961). Radioactive dating of granites from St. Francois Mountains has been performed by 
Allen et al. (1959) and Tilton et al. (1962). The K-Ar and Rb-Sr analyses give ages ranging from 1.2 to about 1.5 billion years.

Paleomagnetism of Precambrian igneous rocks of St. Francois Mountains has been studied extensively by Scharon et al. (1961) who found that most of these rocks were magnetized in a significant direction, revealing after "magnetic washing" a mean virtual geomagnetic pole at $150^{\circ} \mathrm{W}$ longitude and $5^{\circ} \mathrm{N}$ latitude, that is in the vicinity of Christmas Islands in the Pacific. Some rock units, however, showed a scatter in their directions of magnetization, or significant deviations from the average direction, so that presence of stable secondary magnetization could be suspected.

Two areas were selected for study and their location is shown on the geological sketch map in Figure 1.

The rocks of Flint Hill consist of intrusive rhyolite porphyries exposed on the flank of a fairly steep hill. They appear to have been subjected to hydrothermal alteration inferred from the fact that among their component minerals almost all the phenocryst feldspars were altered to sericite and kaolinite and secondary magnetite was found forming rim around altered hornblende. The sampling was conducted at fifteen sites spaced at an average interval of $100 \mathrm{ft}$. and approximately along a topographic contour of the hill. Detailed magnetic surveys of the area together with extensive petrologic and paleomagnetic studies were made by the Department of Earth Sciences, Washington University.

Microscopic investigation by reflected light of polished sections of Flint Hill rhyolite porphyries showed that their main magnetic constituent was magnetite which occurred in

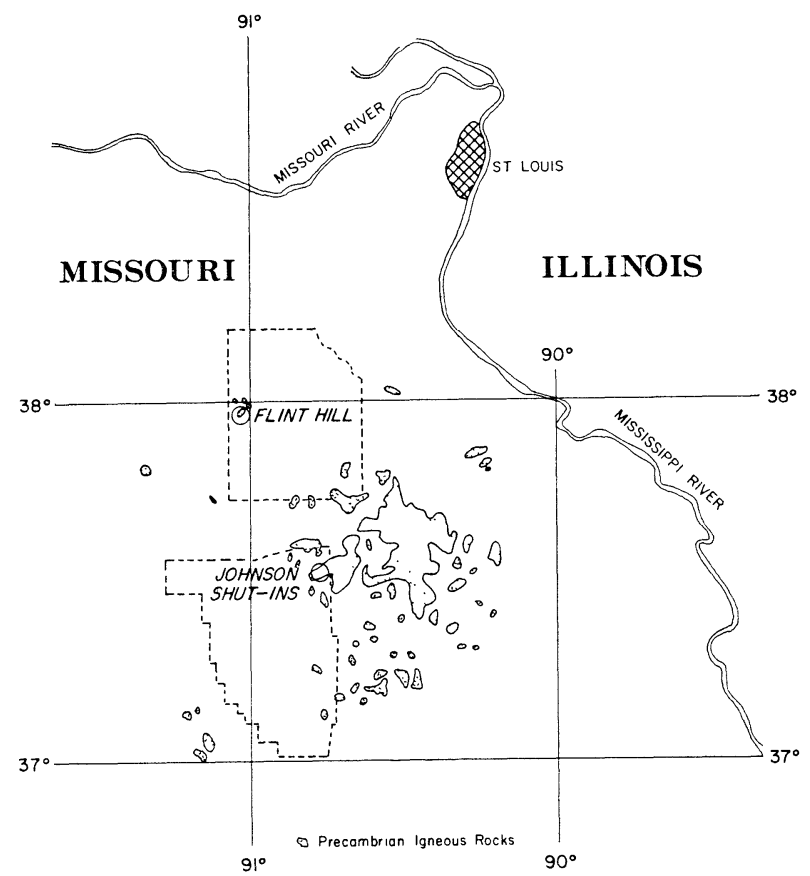

Fig. 1. Geological sketch map of Precambrian igneous province of Missouri. 
Table 1. Natural remanent intensities $\left(J_{n}\right)$ and ratios of TRM $\left(J_{T}\right)$ to $J_{n}$ of rhyolite porphyries of Flint Hill.

\begin{tabular}{c|c|c}
\hline Sample & $J_{n}(\mathrm{emu})$ & $J_{T} / J_{n}$ \\
\hline 1A1 & 0.153 & 0.106 \\
2A1 & 0.292 & 0.061 \\
2B & 0.303 & 0.057 \\
3A2 & 0.386 & 0.048 \\
3C 2 & 0.412 & 0.040 \\
4A1 & 0.049 & 0.525 \\
5B & 0.061 & 0.237 \\
6C1 & 0.024 & 0.496 \\
7A2 & 0.035 & 0.236 \\
8A2 & 0.360 & 0.043 \\
9B2 & 0.060 & 0.240 \\
\hline
\end{tabular}

three distinct forms: as granular phenocrysts, subhedral to euhedral, as small grains in the ground mass, and as rim around gangue minerals. In some specimens exsolved ilmenite was seen in large magnetite phenocrysts and in a few others secondary polycrystalline hematite was in evidence. Only one sample contained hematite alone which could have been of primary origin. A few samples showed traces of chalcopyrite. No maghemite $\left(r-\mathrm{Fe}_{2} \mathrm{O}_{3}\right)$ was found in any of the samples investigated. The amount of magnetic fraction varied from about $2 \%$ to $7 \%$ and the grain diameter from 10 to 100 microns, the size of 10 to 50 microns being the most frequent.

All rhyolite porphyries were strongly magnetic with NRM generally of the order of 0.1 emu (see Table 1).

\section{JOHNSON SHUT-INS}

STRATIGRAPHIC SEQUENCE (AFTER C.C. KU)

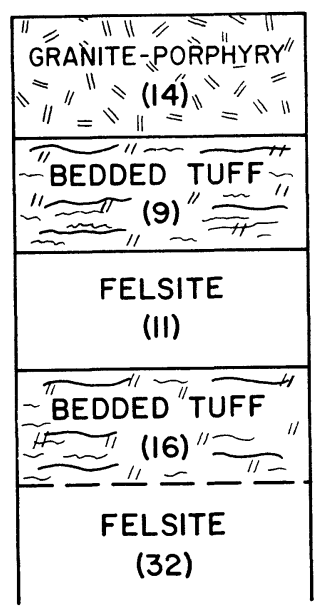

Fig. 2. Simplified sequence of rock units at Johnson Shut-Ins.
The area at Johnson Shut-Ins consists of a sequence of felsites interbedded with tuffs and overlain by granite porphyry. The rock units dip at $18^{\circ}$ to $\mathrm{N}$ with a strike of $\mathrm{N} 70^{\circ} \mathrm{W}$. They appear to be relatively fresh. A simplified diagram of the sequence of the rock units studied is shown in Figure 2. The geology and paleomagnetism of this area have been investigated by C.C. Ku of the Department of Earth Sciences, Washington University.

Polished section investigations of rock units of Johnson Shut-Ins showed that these rocks were relatively poor in iron oxides, the most frequent percentages falling below $1.5 \%$. The felsties contained hematite only. The bedded tuffs also contained hematite with one or two exceptions when, instead, hematite, magnetite and martite were present. The hematite was usually granular and anhedral, (felsite 
Table 2. Virgin NRMs $\left(J_{n}\right)$ and corrected ratios of TRM to NRM $\left(J_{T} / J_{n}\right.$ clean) of rock units at Johnson Shut-Ins.

\begin{tabular}{c|c|c|c}
\hline Rock & Sample & $J_{n}(\mathrm{emu})$ & $\left(J_{T} / J_{n}\right.$ clean $)$ \\
\hline Granite porphyry & $14 \mathrm{E}$ & $0.584 \times 10^{-3}$ & 2.60 \\
$" \#$ Bedded tuff & $14 \mathrm{~F}$ & $0.677 \times 10^{-3}$ & 2.20 \\
Felsite & $9 \mathrm{G}$ & $1.174 \times 10^{-3}$ & 5.25 \\
$"$ & $11 \mathrm{E}$ & $0.167 \times 10^{-3}$ & 2.11 \\
Bedded tuff & $11 \mathrm{~F}$ & $0.121 \times 10^{-3}$ & 2.71 \\
$" \Rightarrow "$ & $16 \mathrm{E}$ & $0.467 \times 10^{-3}$ & 0.628 \\
Felsite & $16 \mathrm{~F}$ & $0.373 \times 10^{-3}$ & 0.641 \\
& $32 \mathrm{E}$ & $0.115 \times 10^{-3}$ & 0.880 \\
\hline
\end{tabular}

No. 11 and tuff No. 16, Figure 2), though in some cases it appeared to have pseudomorphed after magnetite (felsite No. 32). Tuff No. 9 contained magnetite with martite in the form of rims around sub-cubic magnetite grains. The granite porphyry usually contained only granular magnetite, but the samples used in the present investigation contained granular hematite. The grain size of hematite in felsites and tuffs was fairly uniform, mostly about 10 microns in diameter. In tuff No. 16 and the granite porphyry the diameter was 40-100 and 40-50 microns respectively. The size of magnetite grains in tuff No. 9 was 100-150 microns. In all five rock units a certain amount of sub-microscopic size grains of iron oxides was found. No ilmenite or maghemite was detected in any of the samples investigated.

All the rock units at Johnson Shut-Ins were werkly magnetic with NRM of the order of $0.1 \times 20^{-3} \mathrm{emu}$ (see Table 2).

\section{Experimental Procedure}

As a result of the additive property of PTRM, rocks retain a record of the ambient fields and temperature ranges through which they have cooled in these fields so that the total magnetization is a vector sum of all the PTRMs (Thellier, 1951). On destroying by heat the PTRM corresponding to a particular temperature range, the PTRMs imposed at higher temperatures become apparent and, if these represent the original NRM, the well known process of "thermal cleaning" (Irving, 1964) has been accomplished.

Two types of thermal demagnetization techniques have been used to study the changes in NRM produced by heat treatment. In one technique (Wilson, 1962), the NRM of a rock samle is measured with an astatic magnetometer at the temperature to which the sample has been raised. In the other method (Irving, 1961), the NRM is remeasured at room temperature after heating the rock samples to a given temperature and cooling them in zero field.

In the present case the second technique was used in preference to the first. A cubical array of eight cylindrical samples $(2.59 \mathrm{cms}$ diameter and $2.28 \mathrm{cms}$ long) was used and cooling was conducted in a field free space which was maintained by means of a Rubens (1945) coil system fed from a three-component fluxgate magnetometer. The heating and cooling were carried out in a high purity nitrogen atmosphere (maximum $0.002 \%$ oxygen). 
The magnetometer output, operating through a suitable electronic circuit, automatically cancelled the ambient field in the space containing the sample array. The maximum departure from zero field at the center of the array was \pm 3 gammas. The NRM of the samples was remeasured after each cooling and the procedure was repeated for progressively higher temperatures until no significant NRM could be detected in the samples. Since stable secondary magnetization was sought, the number of heating steps at lower temperatures was kept to a minimum. The temperature intervals were made shorter at higher temperatures close to the Curie points of the most important magnetic constituents. The samples were kept at a given temperature for 30 minutes before cooling to a room temperature of about $30^{\circ} \mathrm{C}$. A thermal survey of the interior of the furnace and temperature measurements made in the interior of a test sample indicated that the temperature recorded inside the furnace with a platinum-platinum-rhodium thermocouple was within $\pm 3^{\circ} \mathrm{C}$ of the average temperature of each sample. Although during each cooling a nominal zero field was maintained at the center of the sample array, the variable field gradient in the laboratory generated within the array a transient and non-uniform field of variable direction and magnitude up to 100 gammas. This imperfection was not considered serious.

In addition to thermal demagnetization of NRM several subsidiary experiments were performed. These consisted of (1) alternating field demagnetization ("magnetic washing") of NRM with a maximum peak field of 800 oersted; (2) imposition and measurement of total TRM; and (3) alternating field and thermal demagnetization of the TRM. At all times when not subjected to experiments, the rock cylinders were stored in a suitably constructed mumetal box the field inside which was less than 1 gamma. This was done to prevent the cylinders from acquiring any VRM due to the ambient field in the laboratory.

\section{Experimental Results}

\section{Flint Hill}

The results of thermal demagnetization of NRM of Flint Hill rhyolite porphyies are given in Figures 3 and 4 . Figure 3 shows decay of NRM with temperature, represented by curves of normalized intensity $J_{n T}$ plotted versus temperature, the intensity $J_{n 0}$ corresponding to the NRM at $30^{\circ} \mathrm{C}$. Figure 4 shows the directional changes of NRM after each heating, plotted on a polar equal area net.

With one exception, the thermal decay curves all show that the NRM disappears at about $580^{\circ} \mathrm{C}$. In agreement with the results of microscopic examination, this suggests that magnetite is the main magnetic constituent which carries NRM. On some curves (those for samples $2 \mathrm{~B}, 4 \mathrm{~A} 1$, and $9 \mathrm{~B} 2$ ) there is a faint inflection point suggesting presence of a lower Curie point (about $520^{\circ} \mathrm{C}$ ) constituent, but this could also be a blocking temperature effect. Presence of exsolved ilmenite in some samples indicates that a lowering of the Curie point would not be unexpected. However, the curves do not in general suggest that titaniferous magnetite or ilmenite-magnetite play a significant role in the magnetic properties of these rocks. The one exception to this behaviour is shown by the curve for specimen $8 \mathrm{~A} 2$, which reveals three intervals of more rapid decay of NRM at approximately $400^{\circ}, 580^{\circ}$, and $680^{\circ} \mathrm{C}$, 
where the latter is not well defined. These suggest presence of titanomagnetite, magnetite, and possibly of hematite respectively.

The equal area diagram in Figure 4 shows that the virgin $\left(30^{\circ} \mathrm{C}\right)$ direction of NRM of most samples differs from the average direction of magnetization of rhyolite porphyries of St. Francois Mountains obtained by Scharon and others (1961). This difference remains significant after each heating. However, in sample 3A2 there is a progressive shift of the NRM vector to the position corresponding with the reverse of the average Precambrian direction. This change may have been caused by the removal of a stable secondary PTRM of a direction not greatly different from that of the original NRM. Sample $2 B$ shows an analogous progressive shift in declination, but the inclination of its NRM is at all temperatures different from that found by Scharon and others. The small shift in direction in samples $4 \mathrm{~A} 1,5 \mathrm{~B}$, and $9 \mathrm{~B} 2$ is probably due to removal of a VRM impressed by the earth's present field. The small and insignificant changes in $6 \mathrm{C} 1,7 \mathrm{~A} 2$ and $8 \mathrm{~A} 2$ can be interpreted
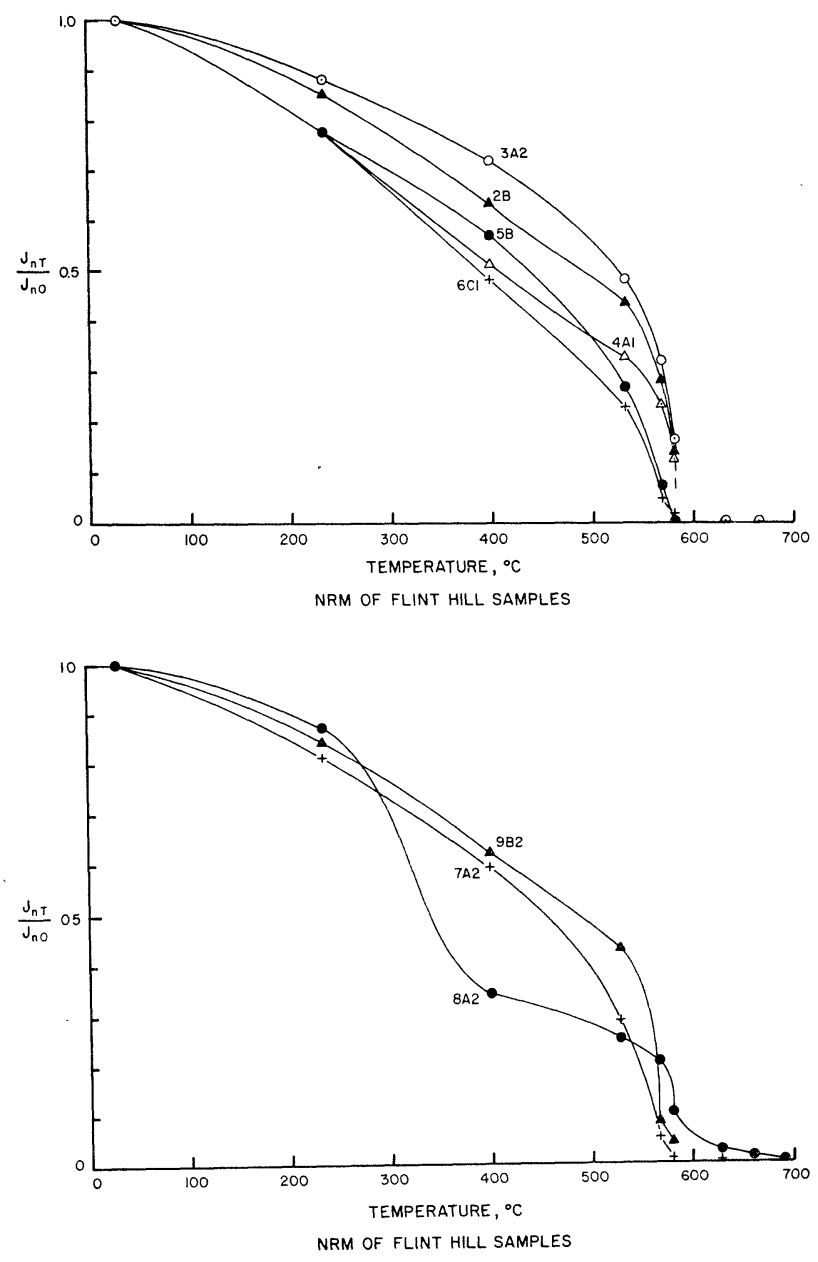

Fig. 3. Decay of NRM with temperature in rhyolite porphyries of Flint Hill. 


\section{FLINT HILL}

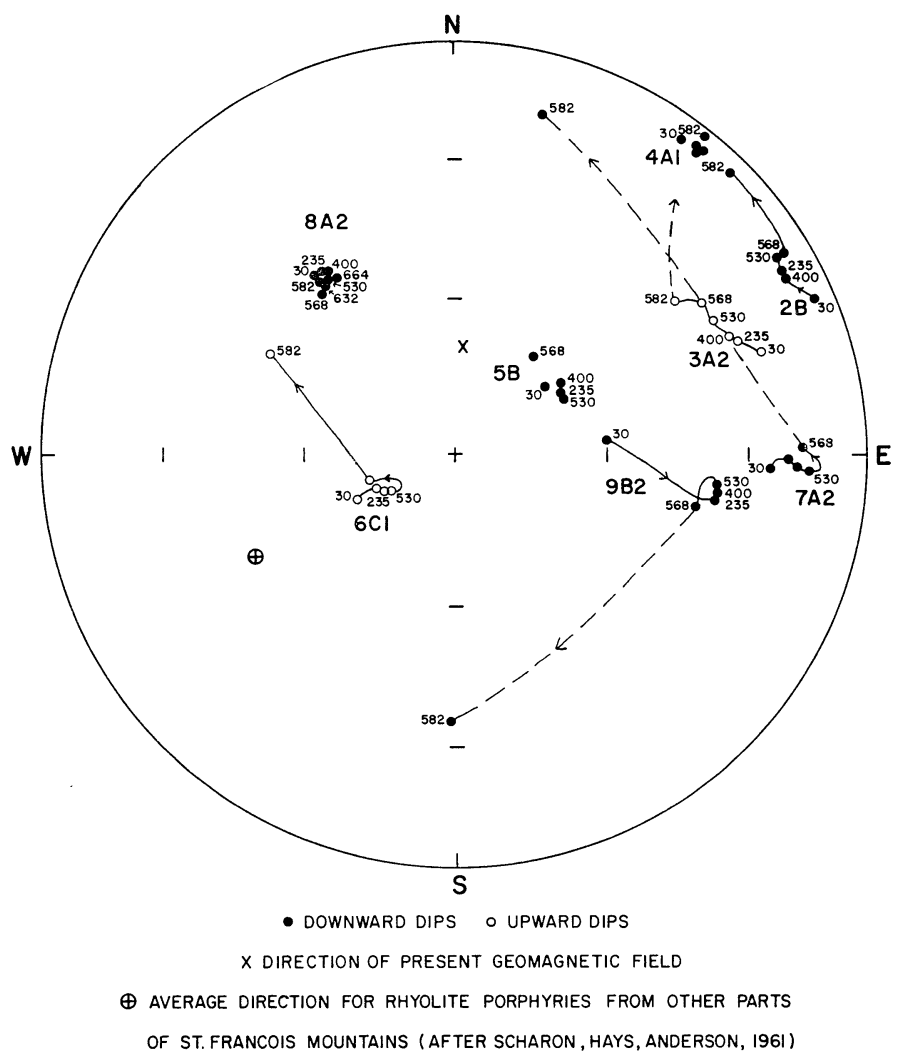

Fig. 4. Change of direction of NRM with temperature in rhyolite porphyries of Flint Hill.

as being due to minute imperfections in the field free space, caused by the variable ambient field gradient in the laboratory. These imperfections account also for the larger and apparently random changes close to the Curie point of magnetite revealed by samples $2 \mathrm{~B}$, $3 \mathrm{~A} 2,5 \mathrm{~B}, 6 \mathrm{C} 1,7 \mathrm{~A} 2$, and $9 \mathrm{~B} 2$ and a similar change (not shown in Figure 4 ) in $8 \mathrm{~A} 1$ in the temperature interval $664^{\circ}-680^{\circ} \mathrm{C}$. The progressive change in the direction of magnetization of $3 \mathrm{~A} 2$ is illustrated in Figure 5 which shows changes with temperature of the total intensity vector projected onto horizontal and vertical planes.

The shape of the thermal demagnetization curves and the behaviour of sample 3A2 suggest a TRM process as the cause of NRM. However, the high intensity of NRM and the absence of maghemite (Nagata, 1961) point to the possibility that it might be a stable IRM produced by strong fields due to lightning. To test this hypothesis additional experiments were performed. A set of rock cylinders was heated to $700^{\circ} \mathrm{C}$ and cooled to room temperature in a field of 0.355 oersted directed parallel to the vertical axes of the cylinders. The resulting total TRM was acquired parallel to the ambient field, the directions falling within $2^{\circ}$ from the axes of the cylinders. This suggested that the rocks and the scatter in their NRM could not be associated with anisotropy in so far as acquisition of TRM was concerned. 

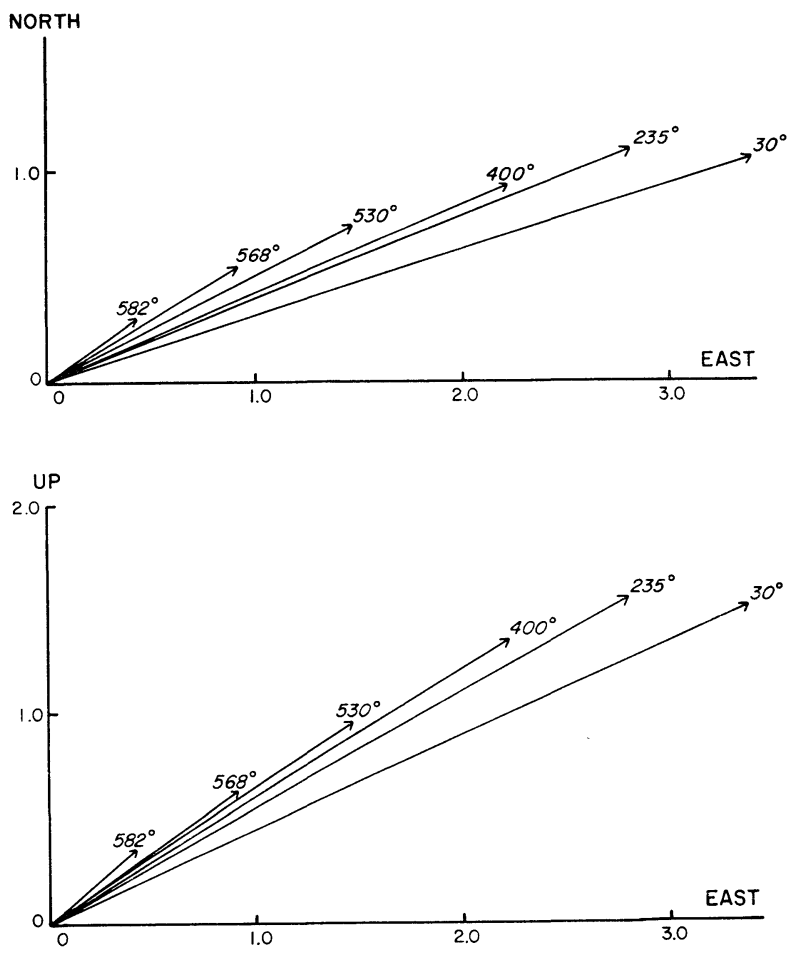

FLINT HILL (3A2)

Fig. 5. Three dimensional representation of the effect of thermal demagnetization of NRM in sample 3A2.

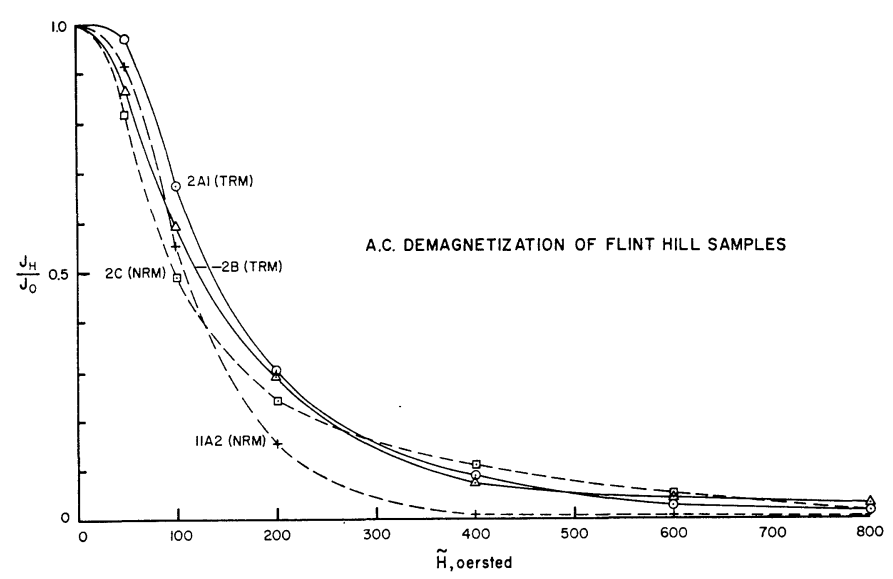

Fig. $6(\mathrm{a})$.

Alternating field demagnetization of the TRM was then carried out and the resulting demagnetization spectra were compared with demagnetization spectra of NRM in equivalent samples. Figure 6 gives the results of such a comparison. In one set of curves (Figure 6(a)) the two types of magnetization appear to be very similar. The sets (b) and (c), however, demonstrate a very distinct difference between NRM and TRM. A 200 oersted field was sufficient to almost completely remove the NRM, while 800 oersteds did not suffice to destroy 


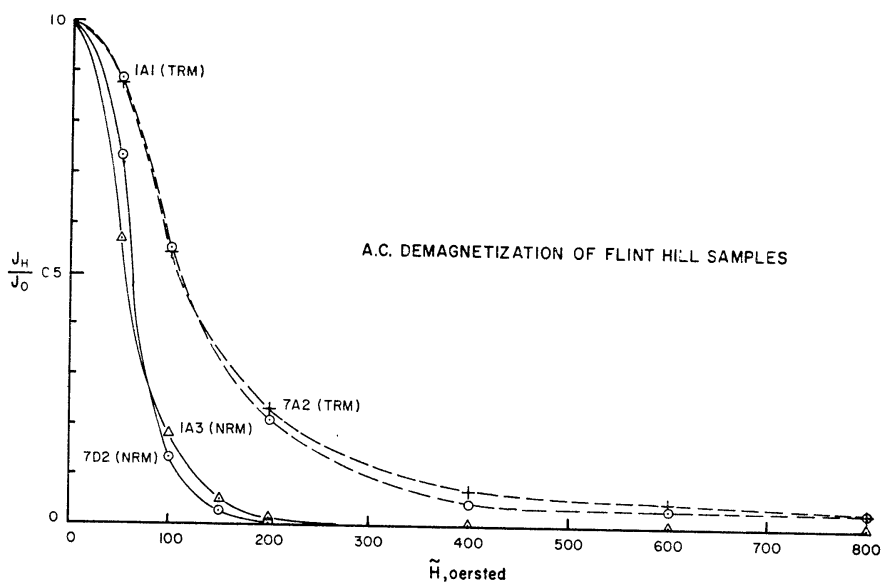

Fig. 6 (b).

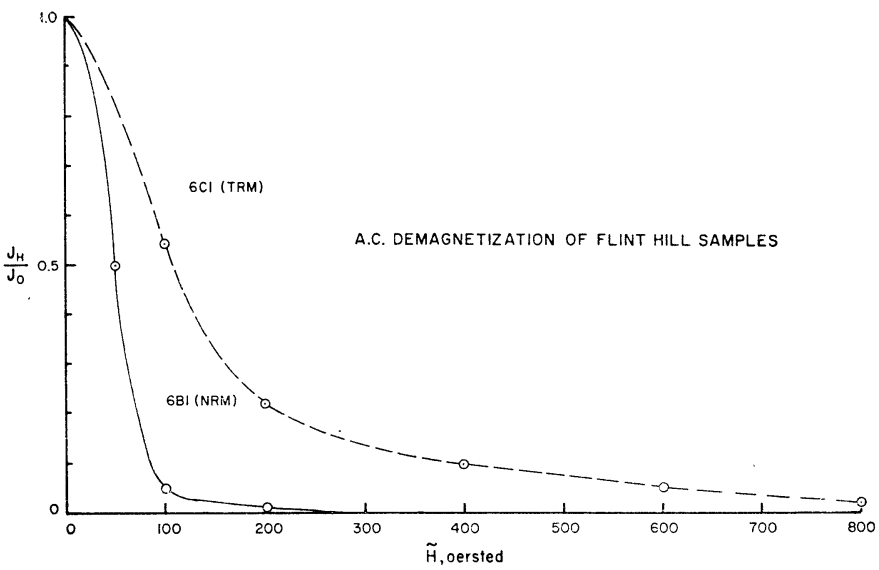

Fig. $6(\mathrm{c})$.

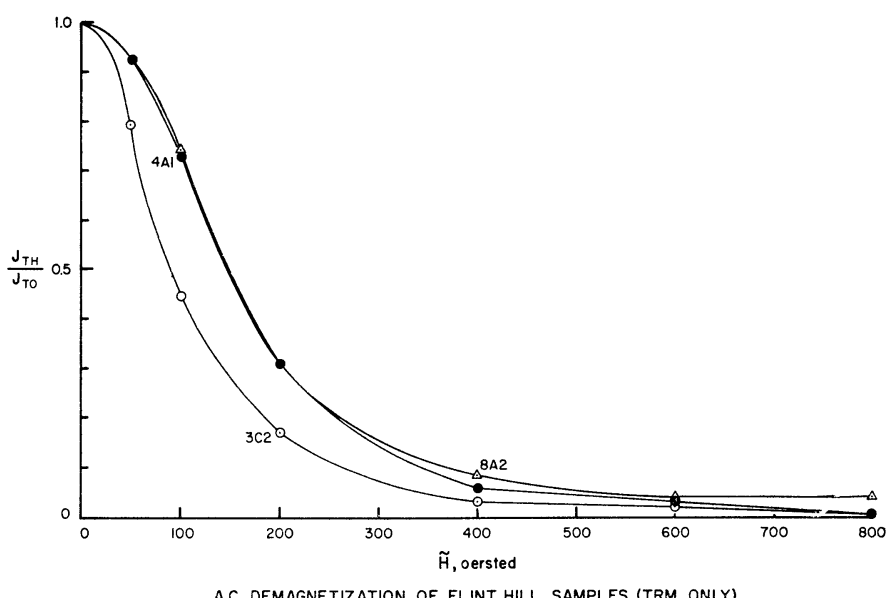

A.C. DEMAGNETIZATION OF FLINT HILL SAMPLES (TRM ONLY)

Fig. $6(\mathrm{~d})$.

Fig. 6. Alternating field demagnetization of Flint Hill rhyolite porphyries. (a), (b), and (c): demagnetization of NRM and TRM; (d) demagnetization of TRM only. 


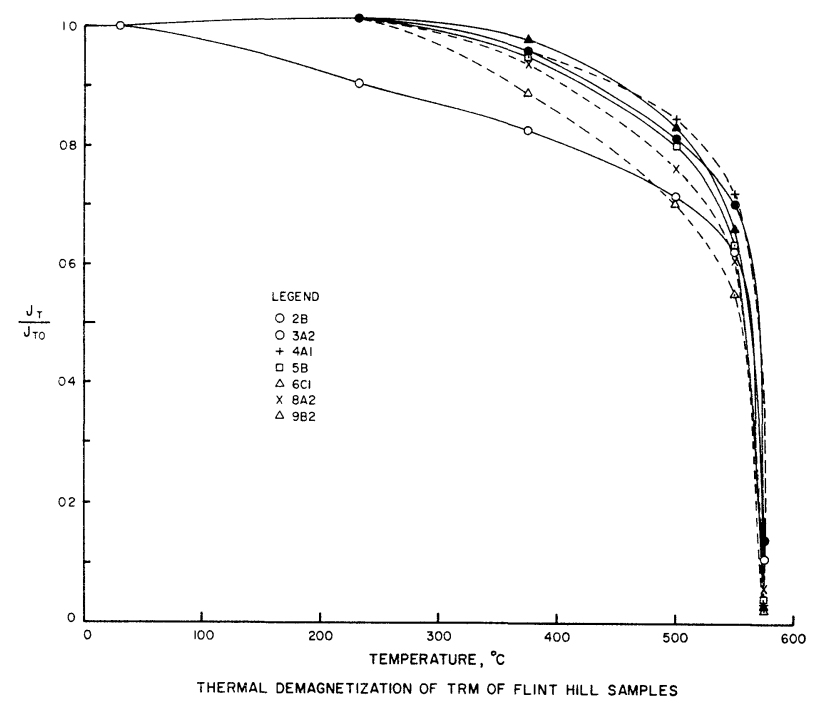

Fig. 7. Decay of TRM with temperature in rhyolite porphyries of Flint Hill.

the TRM. On the other hand, in some samples the TRM was almost completely eliminated by an alternating field with a peak value of 400 oersted (Figure $6(d)$ ). There was no value of peak field which reduced the scatter in the directions of NRM or brought them closer to the average given by Scharon and others.

Figure 7 gives the results of thermal demagnetization of total TRM. Comparing these curves with those of Figure 3, it is seen that although the two sets are similar, the TRM is in general more stable than the NRM, and is not significantly affected by heat treatment below $350^{\circ} \mathrm{C}$. The curves again show that magnetite is the only magnetic constituent in the samples investigated, including sample $8 \mathrm{~A} 2$ in which a three constituent composition was previously indicated by the thermal decay curve of NRM.

Table 1 gives the ratios of total TRM to NRM for the representative samples. All ratios are considerably smaller than unity, the greater part being 0.1 or less. This suggests that a much stronger field would be required to produce a TRM of the same magnitude as the NRM.

\section{Johnson Shut-Ins}

Typical thermal decay curves of NRM of these rock units are reproduced in Figure 8 and the directional changes are shown in Figure 9. All the curves suggest a two constituent composition with Curie points at $580^{\circ}$ and $680^{\circ} \mathrm{C}$, though the lower of these two temperatures may correspond to a blocking tempesature effect rather than to a Curie point. The latter alternative agrees with the information obtained by microscopic examination of most of the rock units which were found to contain hematite only. In tuff No. 9, however, the steeper slope of the curve at $572^{\circ} \mathrm{C}$ may correspond to the presence of magnetite, the slight increase in magnetization above $600^{\circ} \mathrm{C}$ being associated with martite magnetized in opposition to magnetite. It is noteworthy that the granite porphyry and tuff No. 9 demagnetize easily. 
This effect represents the removal of an unstable component of magnetization probably carried by magnetite. This unstable component is very small in tuff No. 16 and felsite No. 32. Felsite No. 11 reveals a progressive increase in NRM on heating up to about $350^{\circ} \mathrm{C}$. In this case the unstable magnetization appears to have been imposed approximately in opposition to the direction of the original NRM.

These deductions, made on the basis of thermal decay curves, are confirmed by studying the directional changes shown in Figure 9. The increase in NRM of felsite No. 11 is clearly associated with removal of VRM imposed by the earth's present field. The direction of NRM changes progressively up to about $350^{\circ} \mathrm{C}$ and shows no significant change between this temperature and $572^{\circ} \mathrm{C}$. It shifts again a little at and above $572^{\circ} \mathrm{C}$, but this change is not systematic and is probably due to the imperfections in the field free space. The removal of unstable secondary magnetization brings the direction of NRM of No. 11 into an approximate coincidence with the reverse of the average direction of magnet!zation of similar rock formations of St. Francois Mountains (Scharon et a1., 1961). Felsite No. 32 shows no significant changes and its NRM has approximately the same direction as that obtained by Scharon and others. Tuff No. 16 also shows very small changes in direction except above $572^{\circ} \mathrm{C}$. It is magnetized in approximately the same direction as felsite No. 11. The demagnetization of tuff No. 9 up to about $500^{\circ} \mathrm{C}$ corresponds probably to removal of VRM, as indicated by the change away from the direction of present field. The change above $600^{\circ} \mathrm{C}$, corresponding to a slight increase in NRM, may be associated with a CRM carried by secondary hematite (martite) derived from magnetite. The change in the direction of NRM of the granite porphyry samples also corresponds to the removal of a small VRM, but the changes are in general small, the magnetization remaining approximately horizontal and

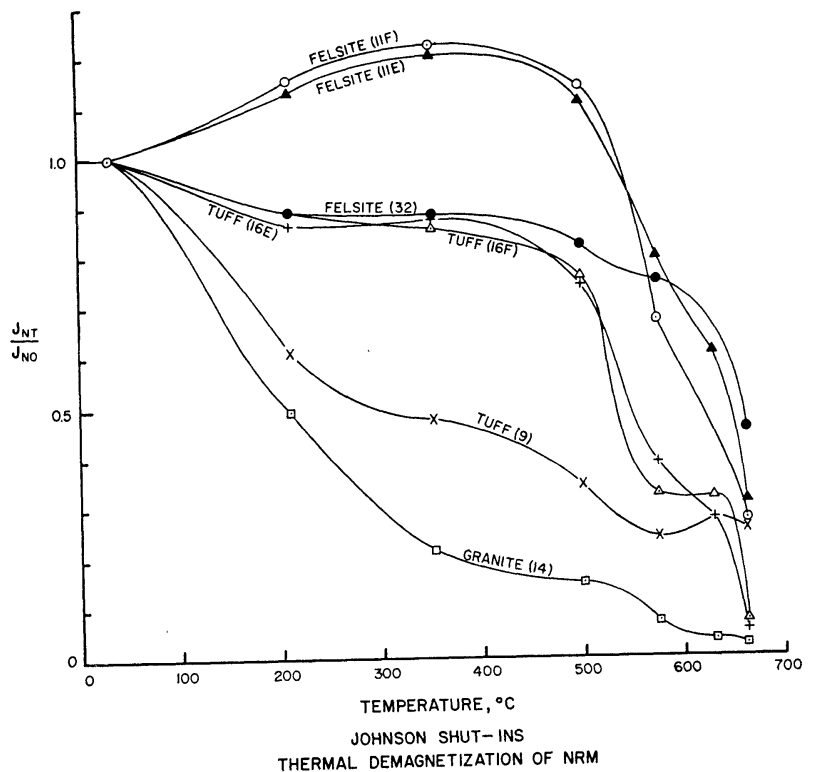

Fig. 8. Change of NRM with temperature in rock samples from Johnson Shut-Ins. 


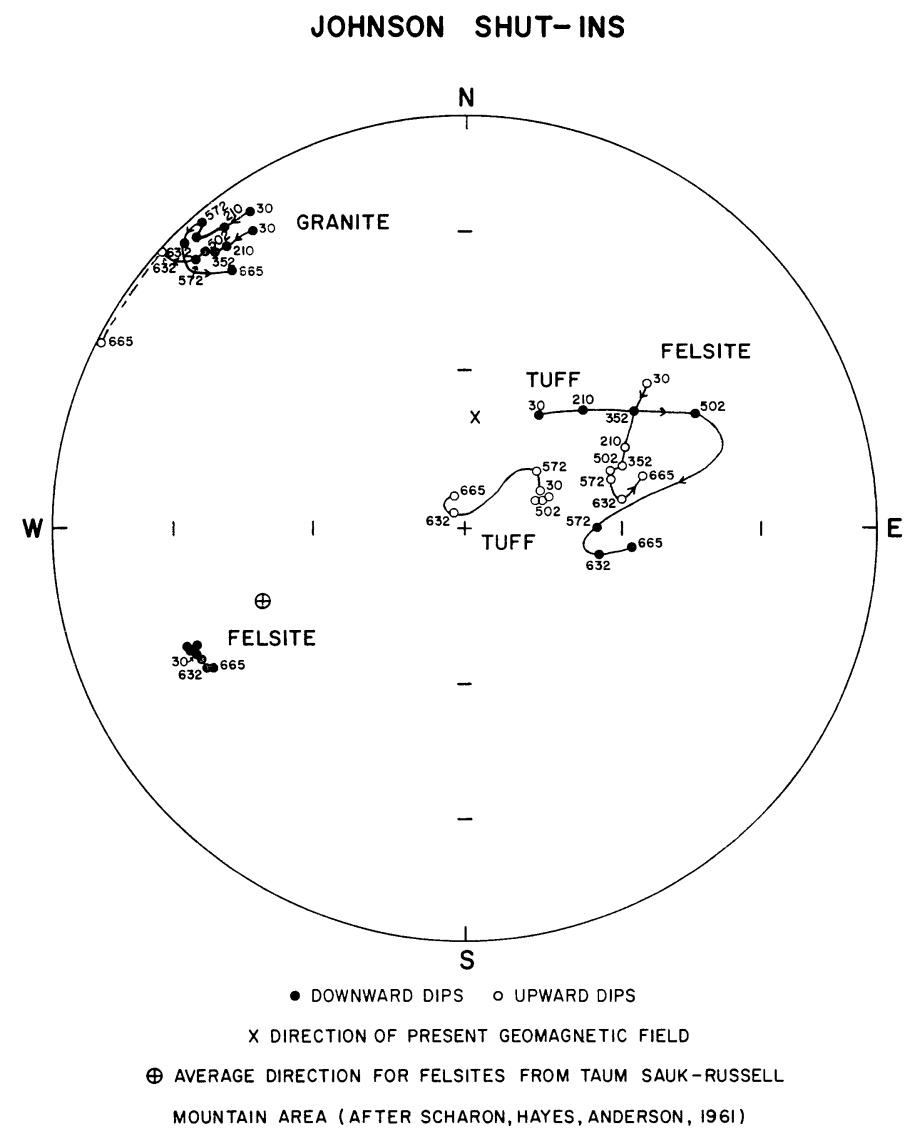

Fig. 9. Directional changes of NRM with temperature in rock somples from Johnson Shut-Ins (directions corrected for the tilt of the strata).

at right angles to that of felsites and of tuff No. 16. The irregularity of behaviour above $572^{\circ} \mathrm{C}$ could be due to the imperfections in the field free space. The variation of NRM with temperature in felsite No. 11 is illustrated in Figure 10 showing the values of total intensity vector projected onto horizontal and vertical planes.

Alternating field demagnetization of samples equivalent to those examined above has been made by $\mathrm{Ku}$ and Scharon and the results of their work are reproduced in Figure 11. The curves reveal a high stability of the NRM of felsites, No. 32 being completely unaffected by the maximum peak field available. Although tuff No. 16 loses relatively easily the soft component of magnetization, its NRM is stable at fields exceeding 300 oersted. In tuff No. 9, $90 \%$ of magnetization is associated with a soft component and stability sets in at 100 oersted. In the granite porphyry sample the soft component of NRM is probably a VRM while the more stable NRM is reversed in relation to it. According to Ku and Scharon (personal communication) the magnetic cleaning of felsites and tuffs was quite effective in reducing the directional scatter to a significant average close to that of the other rock units of St. Francois Mountains. 

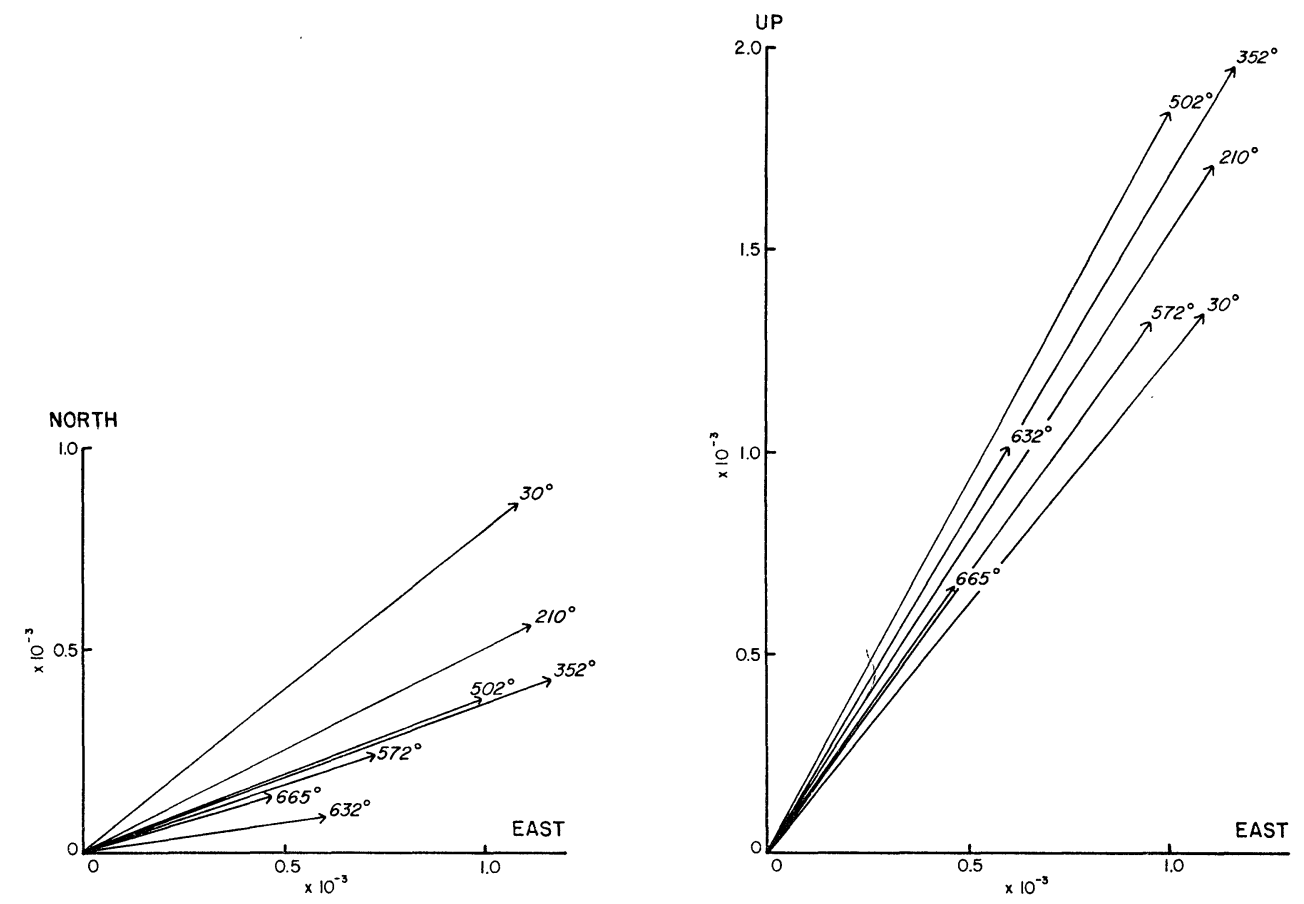

JOHNSON SHUT-INS FELSITE (IIE)

Fig. 10. Three dimensional representation of the effect of thermal demagnetization of NRM of felsite No. 11.

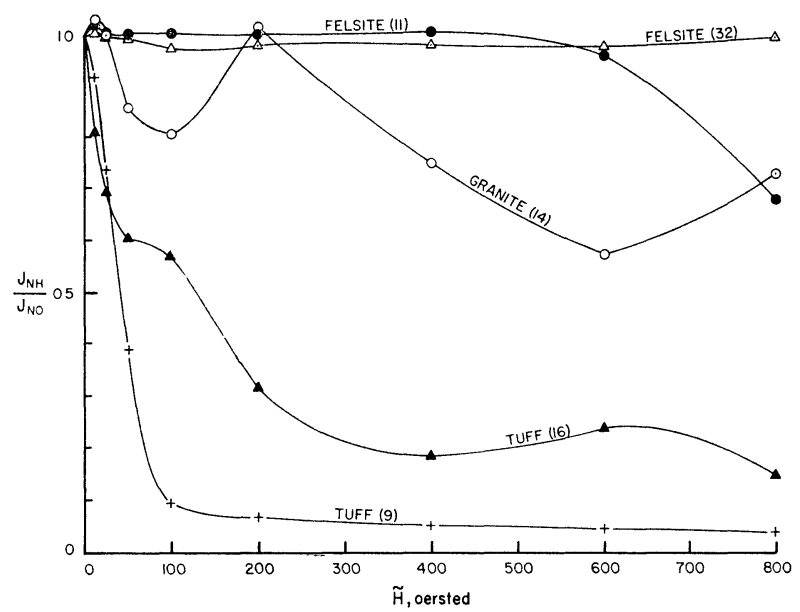

A.C. DEMAGNETIZATION OF JOHNSON SHUT-INS

Fig. 11. Alternating field demagnetization of NRM of rock units of Johnson Shut-Ins (courtesy of C.C. Ku and L. Scharon). 


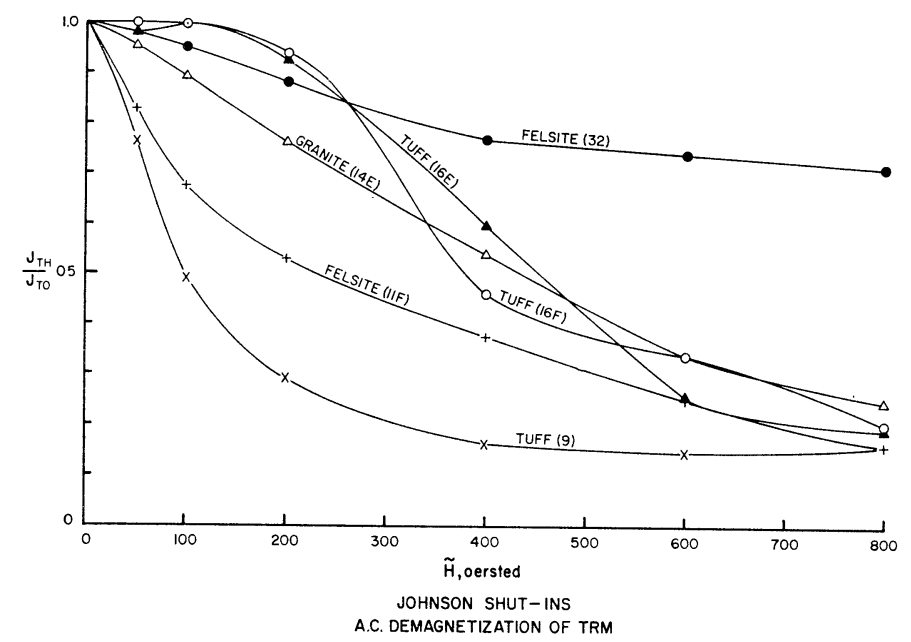

Fig. 12. Alternating field demagnetization of TRM of rock units of Johnson Shut-Ins.

The results of the above experiments suggest that the NRM of felsites and of tuff No. 16 is a TRM and that some of these rock units carry a VRM acquired in the present geomagnetic field. In tuff No. 9 the soft component carried by magnetite is also chiefly a VRM, but the stable component associated with martite could be a CRM. The magnetizatoin of granite porphyry appears to be of entirely secondary origin.

These deductions were confirmed by additional experiments. The magnetic isotropy of these rock units was indicated by the fact that the total TRM was acquired parallel to the direction of the ambient field. The results of alternating field demagnetization of TRM are shown in Figure 12. The stability of TRM of felsite No. 32 compares well with the stability of NRM of the same rock unit. The initial decrease in TRM of felsite No. 11 corresponds with the increase in its reversed NRM shown in Figure 8. The stability of TRM of tuff No. 16 and of granite porphyry is also about the same as that of their NRM. Tuff No. 9 reveals a decrease in the intensity of TRM with increasing peak demagnetizing field. However, there is no decrease for fields greater than 400 oersted, suggesting that, as in the case of NRM, an unstable strong magnetization of magnetite has been removed, leaving a weak but stable magnetization of hematite (martite).

It is, thus, generally concluded that felsites have retained a stable primary NRM dating back to the Precambrian and carry a relatively small unstable secondary VRM. Tuff No. 16 is equally stable and carries very little VRM, while tuff No. 9 and the granite porphyry appear to carry only secondary magnetization.

\section{Discussion}

The results described show that the search for a stable secondary NRM produced by a thermoremanent process has been relatively unsuccessful. The data for the Flint Hill rhyolite porphyries suggest that they carry a stable and strong remanent magnetization produced by an isothermal process which has completely destroyed the original NRM. The one 
possible exception might be the magnetization of sample 3A2, but its high magnitude and the low value of $J_{T} / J_{n}$ (Table 1) suggest that the behaviour on heating as shown in Figure 5 must have been a result of coincidence.

The alternating field demagnetization spectra of the rhyolite porphyries clearly do not resolve the problem of the origin of their NRM. However, the greater stability of TRM shown in Figure 7 suggests an IRM origin.

Detailed studies of IRM imposed by lightning (Cox, 1961; Graham, 1961) have established its relative instability when compared with TRM. Ih some cases, however, lightning produced IRM appears somewhat more stable then an IRM impressed by an artificial pulsed unidirectional field simulating the effect of lightning. Some workers have attributed to lightning also the very strong stable NRM which does not submit to thermal or magnetic cleaning. Theoretically, if the fields produced by lightning are sufficiently high, the high coercivity domains, whose blocking temperatures lie very close to their Curie points, will be affected similarly as in the process of acquisition of TRM. While experience shows that the maximum currents in lightning discharges may occasionally reach 250,000 amps, the majority are usually about one-tenth of this figure. Although it is possible that the Flint Hill rocks might have been magnetized by fields greater than those normally caused by present day lightning, the possibility has to be considered of a more complex process of magnetization. As is well known, the passage of a lightning current is accompanied by strong thermal effects. Such effects could locally affect the magnetic domains with high blocking temperatures even if the field produced by the lightning is not exceptionally high. The magnetization produced in this fashion will be an IRM impressed at a high temperature. Since, in addition, cooling of the rock will take place in the local ambient field, the domains affected by the field due to lightning at a high temperature will be stabilized by the process of cooling. A mechanism of this type could locally impress a magnetization whose stability will be comparable with that of TRM. It is suggested that such a process could be responsible for lightning-produced stable natural intensities. Rocks carrying a secondary magnetization of this type are, of course, useless for paleomagnetic work, but in view of the purpose of the present study the origin of this magnetization had to be investigated.

Investigations of the rock units at Johnson Shut-Ins have also failed to uncover a stable secondary NRM produced by a thermoremanent process. The relatively weak stable NRM of tuff No. 9, left after removal of VRM, could be a CRM acquired as a result of chemical changes involving conversion of magnetite to finely divided martite. However, in the whole sequence of rocks the occurrence of martite is not common (Leung, personal communication) and thus the behaviour observed in tuff No. 9 not typical. The magnetization of granite porphyry may also have been acquired by a chemical process and according to $\mathrm{Ku}$ and Scharon (personal communication) its average direction is not statistically significant. So again there is no case here for the presence of a stable and significant secondary magnetization.

Since removal of VRM by heating to $350^{\circ} \mathrm{C}$ resulted in an increase of NRM in reversely magnetized rocks (felsite No. 11) and in a decrease in those which were normally magnetized, the ratio of TRM to NRM was calculated using the "clean" values of NRM. Table 2 gives 
such corrected values of the ratio which are either greater than unity or close enough to unity to justify the conclusion that the NRM of rock units at Johnson Shut-Ins was impressed by fields of about the same order of magnitude as the present geomagnetic field. The ratios greater than unity may indicate the effect of heat treatment in the laboratory. Heating of hematite bearing rocks in nitrogen sometimes results in reduction of hematite to magnetite (Chamalaun and Creer, 1964), production of which would lead to a larger value of TRM. Occurrence of such a change in the felsites and in tuff No. 16 would in no way invalidate the conclusion that these rock units have retained their original magnetization which is more than 1 billion years old. Since the direction of this original NRM agrees with that found by Scharon for most rock units of the Precambrian igneous province of Southeast Missouri, it is unlikely that the NRM of any of these rocks is masked by stable secondary components of thermoremanent origin.

It must be pointed out that, even in most carefully controlled thermal experiments, physico-chemical changes may take place, the nature of which is not always clear. In the present case, although oxidation of magnetite to hematite was prevented by heating in nitrogen and absence of oxidation was monitored by fresh copper filings, repeated heating did produce such changes. Thus, in some rhyolite porphyry samples $(2 \mathrm{~B}, 6 \mathrm{C} 1,7 \mathrm{~A} 2)$ the total TRM impressed for the second time increased by about 10-15\%. In addition, an increase or decrease in weak field susceptibility was observed in some samples after heating them to high temperatures. Both these effects suggest that separation of iron oxides from ferromagnesian minerals or their reabsorption have taken place. Occurrence of the latter effect is indicated by the behaviour of sample 8A2 (Figures 3 and 7). However, the occurrence of such changes does not materially affect the conclusions drawn from the experiments performed.

\section{Conclusions}

A deliberate search has been made in Precambrian igneous rocks of Missouri for stable secondary magnetization, the presence of which might lead to erroneous conclusions about the direction of the ancient geomagnetic field. The results of this search have been unsuccessful. Although the stable magnetization of Flint Hill rhyolite porphyries could be confused with a magnetization of thermoremanent origin, the results suggest that it has been caused by lightning. A possible CRM of some of the bedded tuffs and of the granite porphyry at Johnson Shut-Ins is stable, but its ocurrence has not significantly affected the overall NRM of the whole sequence of these rock units which are magnetized in the general direction of the Precambrian geomagnetic field.

It is thus concluded that the paleomagnetic investigations made by Scharon and others (1961) have dealt with the original magnetization of these very ancient rocks, not masked by any secondary PTRM or VPTRM.

\section{Acknowledgements}

The rock samples used in this investigation have been collected in the field by members 
of the rock magnetics group of the Department of Earth Sciences, Washington University. We wish to acknowledge in this respect our gratitude to J. Kienzle and C.C. Ku. All microscopic studies of the mineralogy of the rocks were made by Dr. Samuel S. Leung and we thank him for his kind cooperation. We thank Professor L. Scharon of Washington University for the loan of his spinner magnetometer and AC demagnetizer, and for his kind suggestions in the final preparation of the manuscript.

The work was undertaken with the assistance of grant GP-760 from the National Science Foundation whose financial support is gratefully acknowledged.

\section{References}

Allen, V.T., P.M. Hurley, P.M. Fairbairn, and W.H. Pinson, Age of Precambrian igneous rocks of Missouri, Geol. Soc. America Bull., 70, 1560-1561, 1959.

Chamalaun, F.H., Origin of the secondary magnetization of the Old Red Sandstones of the Anglo-Welsh Cuvette, J. Geophys. Res., 69, 4327-4337, 1964.

Chamalaun, F.H., and K.M. Creer, Thermal demagnetization studies of the Old Red Sandstone of the Anglo-Welsh Cuvette, J. Geophys. Res., 69, 1607-1616, 1964.

Cox, A., Anomalous remanent magnetization of basalts, U.S. Geol. Surv. Bull., 1083-E, 131-160, 1961.

Gough, D.I., A. Brock, D.L. Jones, and N.D. Opdyke, The paleomagnetism of the ring complexes at Maragudzi and the Mateke Hills, J. Geophys. Res., 69, 2499-2507, 1964.

Graham, K.W.T., The remagnetization of a surface outcrop by lightning currents, Geophys. J., 6, 85102, 1961.

Hibberd, F.H., An analysis of the positions of the earth's magnetic pole in the geological past, Geophys. J., 6, 221-243, 1962.

Irving, E., Paleomagnetism, John Wiley \& Sons, 1964.

Irving, E., W.A. Robertson, P.M. Stott, D.H. Tarling, and M.A. Ward, Treatment of partially stable sedimentary rocks showing planar distribution of directions of magnetization, J. Geophys. Res., 66, 1927-1933, 1961.

McElhinny, M.W., and N.D. Opdyke, The paleomagnetism of the Precambrian dolerites of Eastern Southern Rhodesia, an example of geologic correlation by rock magnetism, J. Geophys. Res., 69, 2465-2475, 1964.

Nagata, T., Rock Magnetism, Maruzen Co., Tokyo, 1961.

Opdyke, N.D., The paleomagnetism of the Permian red beds of Southwest Tanganyika, J. Geophys. Res., 69, 2477-2487, 1964 a.

Opdyke, N.D. The paleomagnetism of some Triassic red beds from Northern Rhodesia, J. Geophys. Res., 69, 2495-2497, 1964 b.

Robertson, F., C. Tolman and W. Hayes, Igneous rocks of southeastern Missouri, State of Missouri Geol. Survey, in press.

Rubens, S.M., Cube-surface coil for producing a uniform magnetic field, Rev. Sci. Instr., 16, 243-145, 1945.

Scharon, L., W.C. Hayes, and R.E. Anderson, Paleomagnetic investigations in the St. Francois Mountains, State of Missouri Geol. Survey Report No. 26, 106-113, 1961.

State of Missouri Geol. Survey Report No. 26, 1961.

Tilton, G.R., G.W. Wetherill, and G.L. Davis, Mineral ages from the Wichita and Arbuckle Mountains, Oklahoma, and the St. Francis Mountains, Missouri, J. Geophys. Res., 67, 4011-4019, 1962.

Thellier, E., Propriétés magnétiques des terres cuites et des roches, J. Phys. Rad., 12, 205-212, 1951.

Wilson, R.L., Palaeomagnetism in Northern Ireland, Part I, The thermal demagnetization of natural magnetic moments in rocks, Geophys. J., 5, 45-58, 1961. 
Wilson, R.L. An instrument for measuring vector magnetizations at high temperatures, Geophys. J., 7, 125-130, 1962.

Wilson, R.L. Magnetic properties and normal and natural magnetization of Mull lavas, Geophys, J., 8, 424-439, 1964.

Wilson, R.L. and C.W.F. Everitt, Thermal demagnetization of some Parboniferous lavas for palaeo. magnetic purposes, Geophys. J., 8, 149-164, 1963. 